\title{
Disruption of Mitochondrial Respiration Inhibits Volume-Regulated Anion Channels and Provokes Neuronal Cell Swelling
}

\author{
Amanda J. Patel, Inger Lauritzen, Michel Lazdunski, and Eric Honoré \\ Institut de Pharmacologie Moléculaire et Cellulaire, Centre National de la Recherche Scientifique, UPR 411, 06560 \\ Valbonne, France.
}

\begin{abstract}
Hypoxia and inhibitors of mitochondrial respiration impair the regulatory volume decrease (RVD) of cerebellar granule neurons after hypotonic swelling. RVD is linked to the opening of volume-regulated anion channels (VRACs). VRACs are outwardly rectifying, inactivate slowly during maintained depolarization, and are permeable to the cellular organic osmolyte taurine. Channel activation requires nonhydrolytic ATP binding and is not modulated by intracellular ADP. VRAC opening is reversibly depressed by hypoxia and by mitochondrial inhibi-
\end{abstract}

Cell volume regulation has been studied extensively in several mammalian systems, including epithelium, cardiac cells, astrocytes, hepatocytes, and lymphocytes (for review, see Strange et al., 1996). However, neuronal volume regulation mechanisms remain largely unknown. Brain cells are normally protected from volume alterations by a fine regulation of plasma osmolarity that occurs in the kidney. However, both physiological neuronal activity and brain pathologies lead to cell swelling and shrinkage (Lipton, 1973; Ames and Nesbett, 1983; McBain et al., 1990). It is particularly well known that anoxia and ischemia are associated with neuronal cell swelling and subsequent tissue damage (for review, see Rothman and Olney, 1986; Choi and Rothman, 1990; Choi, 1992). Neuronal swelling is also the hallmark of inherited human diseases caused by point mutations in mitochondrial DNA, such as mitochondrial myopathy, encephalopathy, lactic acidosis, and stroke-like episodes (the MELAS syndrome) (Breningstall and Lockman, 1988; Castillo et al., 1995; James et al., 1996; Valanne et al., 1996). The understanding of neuronal cell regulatory volume mechanisms and their modulation by hypoxia could be extremely valuable for designing novel therapeutic strategies for treating some aspects of brain ischemic damage and edema.

During anisotonic swelling, cells have the ability to regulate their volume by a regulatory volume decrease mechanism (RVD) (Strange et al., 1996). RVD is linked to the activation of volumeregulated anion channels (VRACs) and potassium channels. VRACs are permeable to various anions and organic osmolytes, including polyols, methylamines, amino acids, and their deriva-

\footnotetext{
Received Jan. 16, 1998; accepted Feb. 4, 1998.

This work was supported by the Centre National de la Recherche Scientifique. We thank Bristol Myers Squibb for an "Unrestricted Award." A.J.P. was funded by the Philippe Foundation and by the Marie Curie European Economic Community program.

A.J.P. and I.L. contributed equally to this work.

Correspondence should be addressed to Michel Lazdunski, Institut de Pharmacologie Moléculaire et Cellulaire, Centre National de la Recherche Scientifique, UPR 411, 660 route des Lucioles, Sophia Antipolis, 06560 Valbonne, France. Copyright (C) 1998 Society for Neuroscience $0270-6474 / 98 / 183117-07 \$ 05.00 / 0$
}

tors such as oligomycin, rotenone, and antimycin A. These results demonstrate that neuronal VRAC activation and swelling are both tightly linked to cellular energy. Moreover, the findings reported in this work may have a particular significance for inherited mitochondrial human diseases, such as mitochondrial myopathy, encephalopathy, lactic acidosis, and stroke-like episodes (MELAS), which cause brain swelling and edema.

Key words: cerebellar granule neurons; RVD; chloride channels; ICIn; hypoxia; mitochondrial encephalopathy tives (Jackson et al., 1994, 1996; Pasantes-Morales et al., 1994, 1996; Sanchez-Olea et al., 1996; Hand et al., 1997; Manolopoulos et al., 1997; Moran et al., 1997). RVD is accomplished by a selective increase in these volume-sensitive membrane permeabilities, with the accompanying loss of cellular water. These osmoregulatory mechanisms are conserved from marine elasmobranchs through mammals and are of fundamental importance for cells that must adapt to changes in salinity concentration (Strange et al., 1996).

The present report shows that RVD in cerebellar granule cells is linked to the activation of VRACs. We demonstrate that both RVD and VRAC activation, after cell swelling, are impaired by hypoxia and by inhibitors of mitochondrial respiration, and we discuss the possible relevance of these findings for human pathologies.

\section{MATERIALS AND METHODS}

Cerebellar granule cell isolation and culture. Cerebellar granule cells were isolated and cultured as described previously (Varming et al., 1996). Cerebellar granule cells were prepared from 6- to 7-d-old BALB/C mice (Charles River Laboratories). Neurons were seeded on poly-L-lysine (50 $\mu \mathrm{g} / \mathrm{ml}$ )-coated dishes at a density of $2.5 \times 10^{6}$ cells $/ 35 \mathrm{~mm}$ culture dish and cultured in Eagle's Basal Medium (Sigma, St. Louis, MO) supplemented with $10 \%$ fetal calf serum (Life Technologies, Gaithersburg, MD), $25 \mathrm{~mm} \mathrm{KCl}, 0.5 \%$ penicillin-streptomycin. To prevent growth of glial cells, cytosine arabinoside $(10 \mu \mathrm{M})$ was added to the cultures $24 \mathrm{hr}$ after plating. We used 5- to 6-d-old cultures for all studies.

Cell volume measurements. For cell volume measurements, the culture dishes were mounted on an inverted microscope (Olympus Optical, Tokyo, Japan) equipped with differential interference optics and a $40 \times$ oil-immersion objective lens. Images of neurons were sampled using a video camera and stored as TIFF files. The circumference of the soma of single neurons was measured on the monitor with the use of a mouse and analyzed with National Institutes of Health image software. Image acquisition and analysis allows detection of changes with an accuracy of $\pm 2-3 \%$ (Churchwell et al., 1996). Data are presented as means associated with their SEs.

Saline solutions and electrophysiology of granule cells. For cell volume studies, the standard external solution contained (in $\mathrm{mm}$ ): $\mathrm{NaCl} 78, \mathrm{KCl}$ 3.2, $\mathrm{MgCl}_{2} 0.5, \mathrm{CaCl}_{2}$ 1.1, HEPES 12, mannitol 150, glucose 15 , pH 7.4 with $\mathrm{NaOH}(340 \mathrm{mOsm})$. The hypotonic solution $(190 \mathrm{mOsm})$ was the standard solution except mannitol. Osmolarity was measured by the 
freezing point procedure. Hypoxia was performed by bubbling saline solutions with pure nitrogen for at least $30 \mathrm{~min}$ before and during the experiment. Temperature, $\mathrm{pH}$, and osmolarity were checked carefully throughout the duration of the experimentation to ensure that these parameters did not change. Solutions were applied to the cell with a peristaltic pump (Gilson Medical Electric, Middleton, WI) at a flow rate of $5 \mathrm{ml} / \mathrm{min}$.

For electrophysiology of granule neurons, the standard external solution contained (in mM): TEACl $140, \mathrm{MgCl}_{2} 1, \mathrm{CaCl}_{2} 2.5$, HEPES 10, mannitol 50, glucose 5, pH 7.4, with TEAOH (355 mOsm). The hypotonic solution ( $300 \mathrm{mOsm})$ was the standard solution except mannitol. In some experiments, external $\mathrm{Cl}^{-}(140 \mathrm{~mm})$ was substituted with gluconate. To study ionic selectivity of the VRAC, TEACl was substituted with either $\mathrm{NaCl}, \mathrm{NaSCN}, \mathrm{NaBr}, \mathrm{NaI}$, or $\mathrm{Na}$ gluconate. In some experiments taurine permeability was assayed with an external solution containing (in mM): taurine $280, \mathrm{Mg}$ gluconate 1 , HEPES 10 , glucose $5, \mathrm{pH}$ 8.2, with $\mathrm{NaOH}$ (300 mOsm). The internal medium contained (in $\mathrm{mm}$ ): Cs gluconate $155, \mathrm{MgCl}_{2} 3$, EGTA 10, HEPES 10, ATPNa 2 5, pH 7.2, with $\mathrm{CsOH}(350 \mathrm{mOsm})$. With gluconate and taurine solutions, a junction potential of $-4 \mathrm{mV}$ was detected. In some outside-out experiments, internal gluconate was substituted with $\mathrm{Cl}^{-}$(as indicated in Results). For cell-attached experiments, both the bath and pipette media contained the standard external TEACl solution. The hypotonic solution was the TEACl solution diluted by $30 \%(220 \mathrm{mOsm})$. Electrophysiological procedures have been described previously elsewhere (Honoré et al., 1992). Electrophysiological results are presented as means associated with their SEs. $n$ represents the number of cells investigated in each experimental condition.

Cloning of ICln, Xenopus oocyte injection, and electrophysiology. The rat ICln cDNA was cloned (accession number D13985) as follows. A 770 bp fragment was amplified from reverse-transcribed rat lung total RNA using primers 5'-CCGCTCGAGGTTCCTGTGGAGCAATG-3' and 5'CCGCTCGAGTAAGT CACACGAGTCAT-3' containing XhoI restriction sites. The fragment was digested with $X h o I$ and cloned into the vector $\mathrm{pEXO}$, and the sequence was verified using an automatic sequencer (Applied Biosystems, Foster City, CA). The vector was linearized using $X b a$ I to synthesize cRNA for injection into oocytes. Oocyte isolation, injection, and culture has been described previously elsewhere (Honoré et al., 1992). ICln synthetic mRNA (3 ng) was injected into oocytes. The oocytes were maintained at $25^{\circ} \mathrm{C}$ and assayed $48 \mathrm{hr}$ after injection. For oocyte electrophysiology of ICln, the standard external solution contained (in $\mathrm{mm}$ ): $\mathrm{NaCl} 96, \mathrm{KCl} 2, \mathrm{MgCl}_{2} 2, \mathrm{CaCl}_{2} 1.8$, HEPES 10, pH 7.4, with $\mathrm{NaOH}$ (215 mOsm). To lower external $\mathrm{Cl}^{-}, 96$ $\mathrm{mm} \mathrm{Cl}{ }^{-}$was substituted with gluconate. For recording of volumeactivated $\mathrm{Cl}^{-}$channels, the isotonic solution was (in $\mathrm{mM}$ ): $\mathrm{CsCl} \mathrm{48,}$ $\mathrm{BaCl}_{2} 1, \mathrm{MgCl}_{2} 1, \mathrm{CaCl}_{2}$ 0.9, mannitol 110, HEPES 5, pH 7.4, with $\mathrm{CsOH}(220 \mathrm{mOsm})$. The hypotonic solution was the same as the isotonic solution except mannitol $(110 \mathrm{mOsm})$. To lower external $\mathrm{Cl}^{-}, 48 \mathrm{~mm}$ $\mathrm{Cl}^{-}$was substituted with gluconate.

Pharmacological agents. Stock solutions of SITS, DIDS, and 5-nitro2-(3-phenylpropylamino) benzoic acid (NPPB) were made in DMSO at the concentration of $100 \mathrm{~mm}$. Niflumic acid and 9-anthracen carboxylic acid were dissolved in $0.1 \mathrm{~N} \mathrm{NaOH}$ at a concentration of $100 \mathrm{~mm}$. The oligomycin stock solution was made in ethanol at a concentration of 2.5 $\mathrm{mg} / \mathrm{ml}$. Rotenone and antimycin A were dissolved in ethanol at a concentration of $100 \mathrm{~mm}$. Solvents were always included in the control solutions. All chemicals used in this study were purchased from Sigma.

\section{RESULTS}

Volume regulation of cerebellar granule cells was studied in normoxic and hypoxic conditions. Hypoxia either was performed directly by bubbling pure nitrogen or its effects were chemically mimicked using oligomycin, a specific blocker of the F1 unit of the mitochondrial ATPase. Figure $1 A$ shows that in normoxic conditions, granule cells regulate their volume during an anisotonic challenge (also see inset in Fig. $1 B$ ). Decreasing the osmolarity from 340 to 190 mOsm (constant ionic strength) led to a rapid swelling followed by a decrease in cell volume (RVD). Cells recovered $55 \%$ of their initial volume after 20 min of hypoosmolarity. By contrast, during hypoxia, no recovery occurred and cell swelling increased throughout the anisotonic challenge. Figure $1 B$ illustrates the volume regulation after $20 \mathrm{~min}$ of
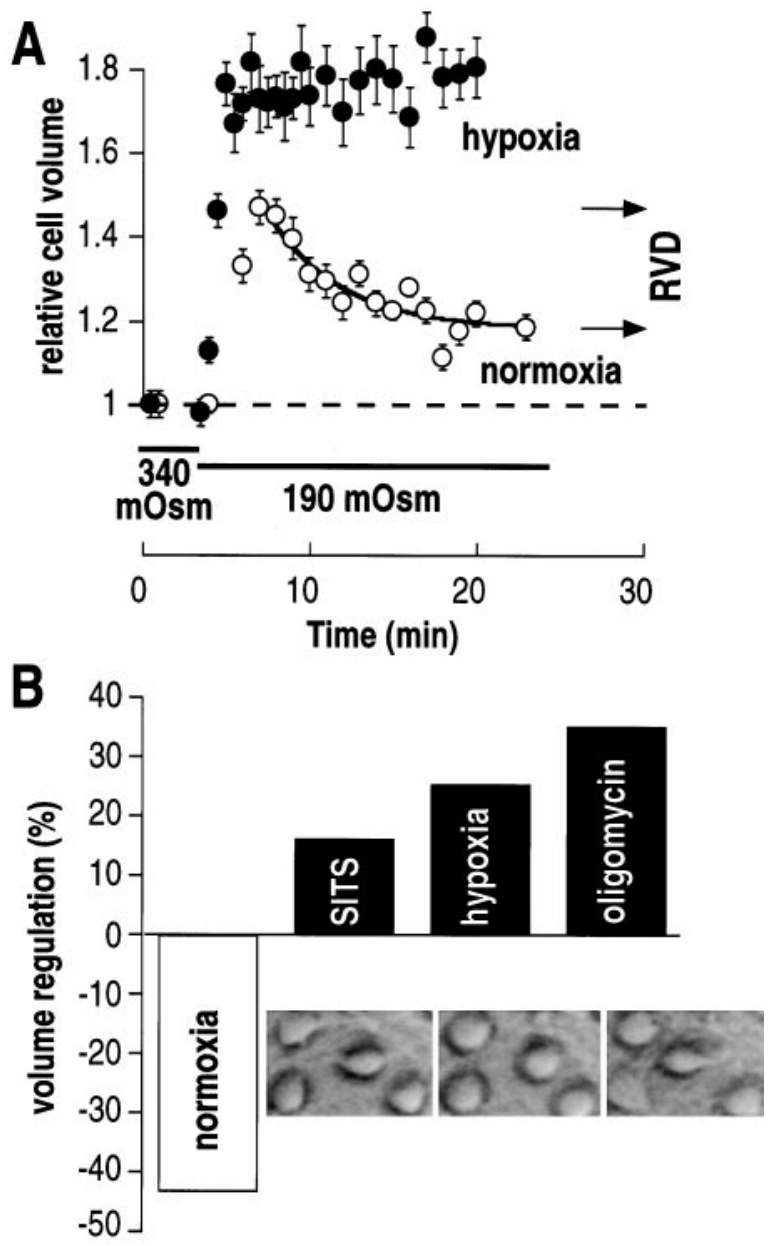

Figure 1. Hypoxic inhibition of regulatory volume decrease in cerebellar granule cells. $A$, Time course of cell swelling and RVD in normoxic and hypoxic conditions. Ten cells were analyzed in each condition, and means associated with their SEs are illustrated. The isotonic and hypotonic osmolarities were 340 and $190 \mathrm{mOsm}$, respectively. B, Percentage of volume regulation after $20 \mathrm{~min}$ in hypotonic conditions $(190 \mathrm{mOsm})$. Thirteen cells were analyzed in each condition. SITS and oligomycin concentrations were $100 \mu \mathrm{M}$ and $2.5 \mu \mathrm{g} / \mathrm{ml}$, respectively. Hypoxia and pharmacological agents were applied in isotonic conditions for $4 \mathrm{~min}$ before and during the hypotonic challenge. The inset shows cell bodies in isotonic condition (340 mOsm) (left panel), 4 min after hypotonic stimulation (middle panel), and $20 \mathrm{~min}$ after hypotonic stimulation (right panel).

hypo-osmolarity in normoxic, hypoxic, and hypoxic-like conditions (oligomycin) and in the presence of the $\mathrm{Cl}^{-}$channel inhibitor SITS. During hypoxia or after oligomycin treatment and in the presence of SITS, RVD was clearly impaired. In isotonic conditions, no volume alteration was detected after 30 min under hypoxic conditions or in the presence of SITS (not shown).

Figure $2 A$ illustrates the changes in membrane potential of a granule cell recorded with the patch-clamp whole-cell configuration during hypotonic stimulation. To block $\mathrm{K}^{+}$channels and to avoid $\mathrm{Na}^{+}$channel current, the intracellular solution contained $\mathrm{Cs}^{+}$(instead of $\mathrm{K}^{+}$), and the extracellular $\mathrm{Na}^{+}$was substituted with $\mathrm{TEA}^{+}$. Furthermore, internal free calcium was chelated with EGTA and the internal $\mathrm{Cl}^{-}$concentration was kept low (6 mM). The contribution of $\mathrm{Cl}^{-}$channel activity to the setting of the resting membrane potential was assayed by substituting external $\mathrm{Cl}^{-}$with gluconate. In isotonic conditions (355 mOsm), the cell 

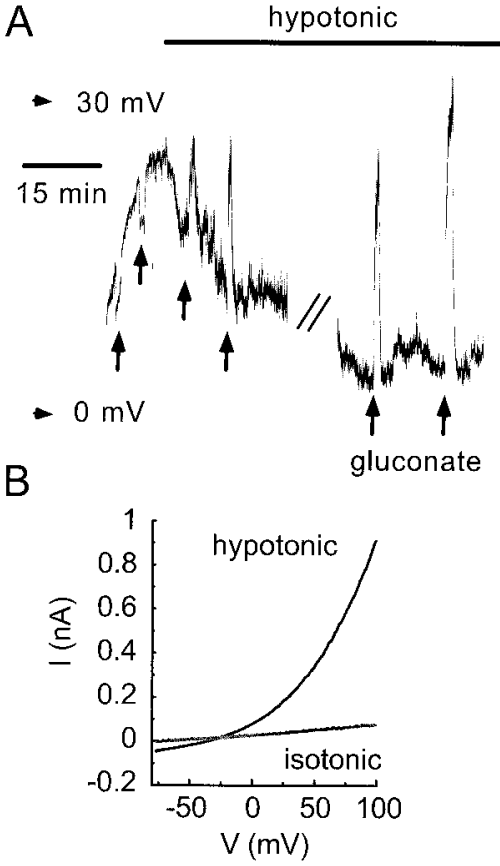

Figure 2. Volume-regulated anion channels in cerebellar granule cells. $A$, Membrane potential recordings in isotonic ( $355 \mathrm{mOsm})$ and hypotonic conditions $(300 \mathrm{mOsm})$. The contribution of $\mathrm{Cl}^{-}$channels to the setting of the resting membrane potential was assayed by substituting $\mathrm{Cl}^{-}$with gluconate (indicated by arrows). $B$, Current-voltage relationship of volume-sensitive anionic channels in isotonic and hypotonic conditions. The holding potential was $-80 \mathrm{mV}$, and the cell was depolarized to 100 $\mathrm{mV}$ with a voltage ramp of $500 \mathrm{msec}$ in duration. $C$, Current traces recorded in hypotonic conditions (300 mOsm). The cell was held at -80 $\mathrm{mV}$ and depolarized to $+50 \mathrm{mV}$ by $10 \mathrm{mV}$ increments. $D$, Pharmacology of the granule cell VRAC. Six cells were analyzed in each condition, and current amplitudes were measured at $+100 \mathrm{mV}$. SITS, DIDS, 9AC, and niflumic acids were added at a concentration of $1 \mathrm{mM}$. NPPB concentration was $0.1 \mathrm{~mm}$. In all experiments, cells were dialyzed with an internal medium containing $6 \mathrm{mM} \mathrm{Cl}^{-}$and $5 \mathrm{~mm} \mathrm{ATP.}$

was depolarized to positive values and removal of external $\mathrm{Cl}^{-}$ led to small hyperpolarizations (a junction potential of $-4 \mathrm{mV}$ was detected under these conditions). When the cell was challenged with a hypotonic solution (300 mOsm), the cell gradually polarized to more negative potentials $(n=9)$. Removal of external $\mathrm{Cl}^{-}$(substituted with gluconate) induced increasing depolarizations in hypo-osmotic conditions (31 $\pm 4 \mathrm{mV} ; n=9)$. Figure $2 B$ shows the $I-V$ curves of the currents recorded in either isotonic or hypotonic conditions. The current induced in hypotonic conditions was outwardly rectifying with a reversal potential of $-48.5 \pm 1.5 \mathrm{mV}(n=31)$. When most of the external $\mathrm{Cl}^{-}$was substituted with gluconate, the amplitude of the outward current was reduced drastically, and the reversal potential was shifted to $-18.8 \pm 3.3 \mathrm{mV}(n=8)$. Figure $2 \mathrm{C}$ shows the current traces recorded during increasing depolarization pulses in hypotonic conditions. The outward current recorded in hypotonic conditions shows a slow time-dependent inactivation at positive potentials. Figure $2 D$ illustrates the pharmacology of the $\mathrm{Cl}^{-}$current activated by cell swelling. The $\mathrm{Cl}^{-}$current was sensitive to the classic $\mathrm{Cl}^{-}$channel blockers SITS, DIDS, NPPB, and niflumic acid but was resistant to anthracene-9-carboxylic acid (9AC).

Figure 3 illustrates the single-channel properties of the volumesensitive $\mathrm{Cl}^{-}$channels in granule cells. Single-channel recordings at different membrane potentials in an outside-out patch $(6 \mathrm{~mm}$ intracellular $\mathrm{Cl}^{-}$concentration) are shown in Figure $3 A$. Similar
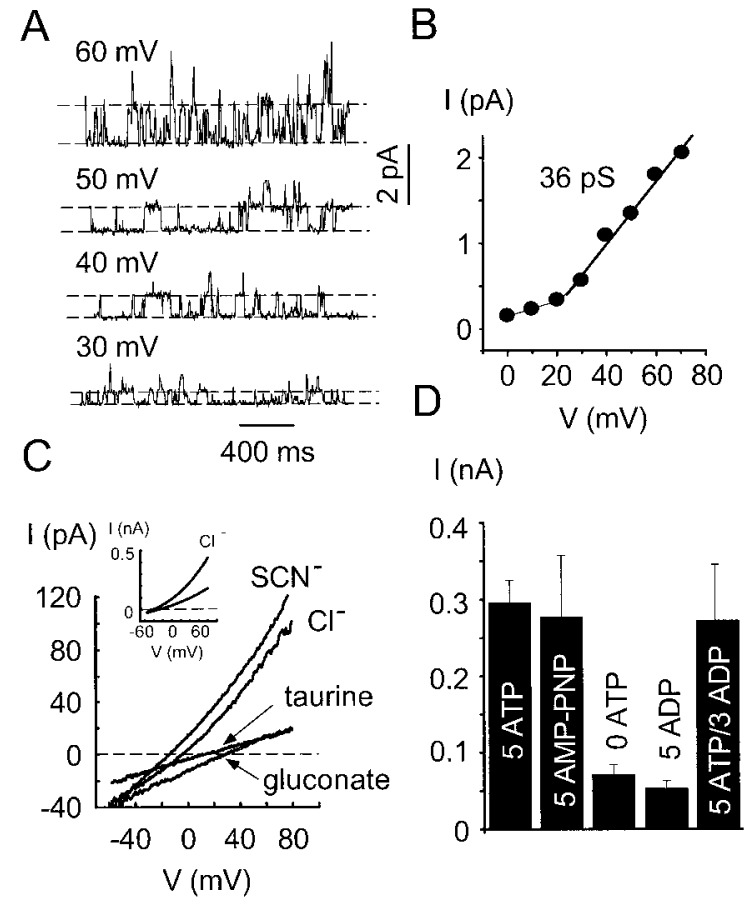

Figure 3. Single-channel properties of granule cell VRAC. $A$, Singlechannel currents from an outside-out patch recorded at different membrane potentials (as indicated) in hypotonic conditions. The internal medium contained $6 \mathrm{mM} \mathrm{Cl}^{-}$and $5 \mathrm{mM}$ ATP. $B, I-V$ curve of the patch illustrated in $A$. The single-channel conductance measured between +30 and $+70 \mathrm{mV}$ was $36 \mathrm{pS}$. $C, I-V$ curves of an outside-out patch constructed with a voltage ramp protocol in hypotonic conditions. The holding potential was $-60 \mathrm{mV}$, and the patch was depolarized to $+80 \mathrm{mV}$ with a voltage ramp of $500 \mathrm{msec}$ in duration. In this experiment external $\mathrm{Cl}^{-}$was substituted with various anions (as indicated). The internal medium contained $161 \mathrm{mM} \mathrm{Cl}^{-}$. The inset shows $I-V$ curves of an outside-out patch excised in the presence $6 \mathrm{~mm}$ internal $\mathrm{Cl}^{-}$. In this experiment the external $\mathrm{Cl}^{-}$concentration was reduced to $6 \mathrm{~mm}$ by substitution with gluconate (bottom trace). $D$, Role of intracellular nucleotides in VRAC activation. Current amplitudes of outside-out patches measured at +80 $\mathrm{mV}$ in different nucleotide conditions (as indicated). Eight patches were analyzed in each condition. In these experiments the internal medium contained $6 \mathrm{mM} \mathrm{Cl}^{-}$, and the external osmolarity was $300 \mathrm{mOsm}$.

to that of whole-cell recordings, the single-channel $I-V$ curve was outwardly rectifying (Fig. $3 B$ ). The inset in Figure $3 C$ shows that when external $\mathrm{Cl}^{-}$was substituted with gluconate, the amplitude of the outward current decreased, and the reversal potential shifted to positive values. The single-channel conductance measured between +30 and $+70 \mathrm{mV}$ was $36 \pm 6 \mathrm{pS}(n=6)$. External $\mathrm{Cl}^{-}$was substituted with various anions to study the ionic specificity of the volume-sensitive anion channel (Fig. $3 C$ ). In these experiments, the internal medium contained $\mathrm{Cl}^{-}$instead of gluconate. Reversal potentials were $-2.4 \pm 0.6 \mathrm{mV}(n=23)$, $-14.6 \pm 1.2 \mathrm{mV}(n=5),-7.8 \pm 1.9 \mathrm{mV}(n=7),-4 \pm 1.5 \mathrm{mV}$ $(n=7),+21.5 \pm 0.8 \mathrm{mV}(n=7)$, and $+39 \pm 0.4 \mathrm{mV}(n=8)$ in the presence of external $\mathrm{Cl}^{-}, \mathrm{SCN}^{-}, \mathrm{I}^{-}, \mathrm{Br}^{-}$, taurine, $\mathrm{pH} 8.2$, and gluconate, respectively (corrected from junction potentials). Current amplitudes were measured in outside-out patches containing different nucleotide conditions. Channel activity was significantly decreased when intracellular ATP was omitted. When ATP was substituted with the nonhydrolyzable analog AMP- $\beta, \gamma-$ imidoadenosine 5', triphosphate (PNP), channel activity was similar to that recorded in the presence of ATP. Furthermore, ADP was unable to substitute for ATP. Finally, addition of ADP in the presence of ATP did not affect channel activity. 


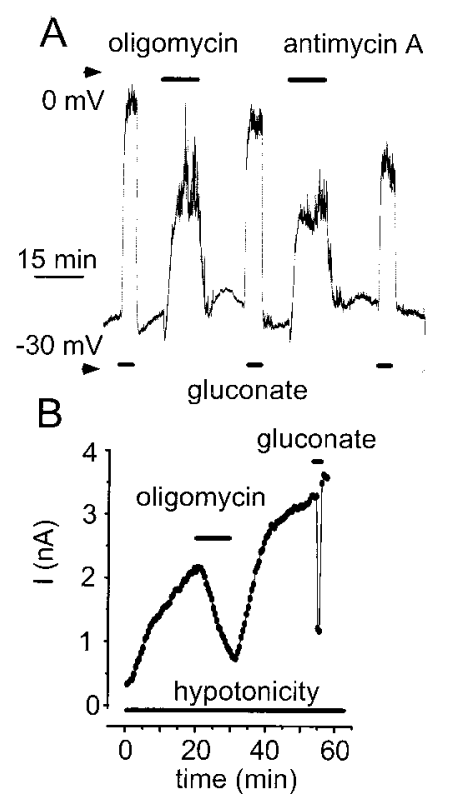

C
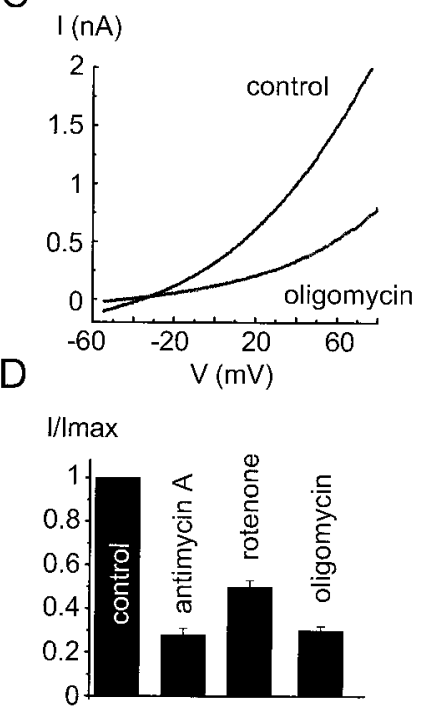

Figure 4. Effects of chemical hypoxia on whole-cell VRAC current of granule cells. $A$, Reversible depolarizations induced by oligomycin $(2.5$ $\mu \mathrm{g} / \mathrm{ml})$ and antimycin A $(10 \mu \mathrm{M})$ in a cell dialyzed with $5 \mathrm{~mm}$ ATP and 6 $\mathrm{mM} \mathrm{Cl}^{-}$. The cell was maintained in hypotonic conditions (300 mOsm), and the contribution of $\mathrm{Cl}^{-}$to the setting of the membrane potential was assayed by substituting external $\mathrm{Cl}^{-}$with gluconate (as indicated). $B$, Reversible effect of oligomycin on the whole-cell VRAC current recorded in hypotonic conditions (300 mOsm). The current amplitude was measured at $+80 \mathrm{mV}$. $C$, Effects of oligomycin on the VRAC $I-V$ curve recorded with a voltage ramp. The holding potential was $-60 \mathrm{mV}$, and the cell was depolarized to $+80 \mathrm{mV}$ with a ramp of $500 \mathrm{msec}$ in duration. $D$, Effects of several metabolic inhibitors on the whole-cell $\mathrm{Cl}^{-}$current recorded in hypotonic conditions (300 mOsm) and measured at $+80 \mathrm{mV}$. Antimycin A and rotenone concentrations were $10 \mu \mathrm{M}$; oligomycin concentration was $2.5 \mu \mathrm{g} / \mathrm{ml}$. Eight cells were analyzed in each condition.

Figure $4 A$ shows that oligomycin (a specific blocker of the F1 unit of the mitochondrial ATPase) and antimycin A (a proximal inhibitor of the mitochondrial electron transport chain) induced reversible depolarizations of granule cells dialyzed in the presence of $5 \mathrm{~mm}$ ATP and maintained in hypotonic conditions (300 mOsm). Similarly, the whole-cell VRAC current recorded in the presence of internal ATP was reversibly inhibited by oligomycin in hypotonic conditions (Fig. 4B,C). Oligomycin inhibited the VRAC current at all potentials (Fig. $4 C$ ). Figure $4 D$ summarizes the effects of several metabolic inhibitors on VRAC recorded in hypotonic conditions (300 mOsm). Antimycin A and rotenone, which are proximal inhibitors of the electron transport chain and oligomycin, an ATP synthase inhibitor, reversibly inhibited the whole-cell $\mathrm{Cl}^{-}$current recorded in the presence of internal ATP. Similar inhibition of VRAC currents by oligomycin was observed in other cell types, including simian virus 40 transformed African green monkey kidney (COS), Madin-Derby canine kidney (MDCK), NIE115 neuroblastoma cells, and human monocytes ( $n=10$; data not shown). No effect of 5 mM DTT (a strong reducing agent) and of $0.5 \mathrm{~mm}$ diphenylene iodinium (DPI) [an inhibitor of $\mathrm{NADP}(\mathrm{H})$ oxidase] was observed $(n=5$; data not shown).

Figure $5 A$ shows that hypoxia performed by bubbling pure nitrogen induced a reversible inhibition $(50.6 \pm 9.3 \% ; n=5)$ of the $\mathrm{Cl}^{-}$current recorded in the cell-attached configuration under hypotonic conditions. Similarly, treatments that mimic hypoxia
A

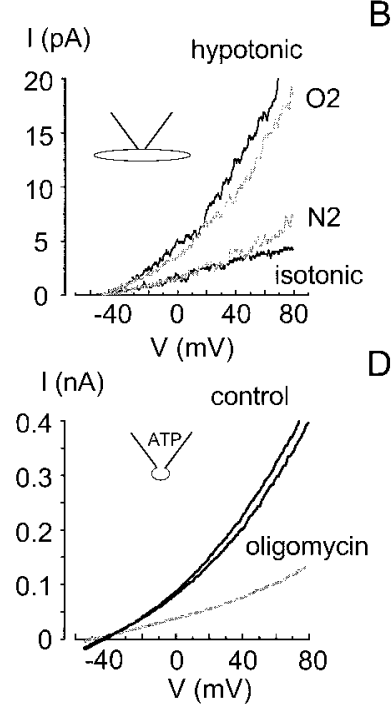

B

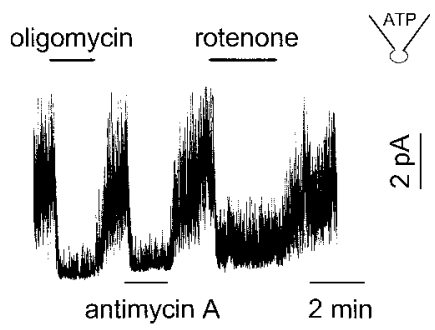

D

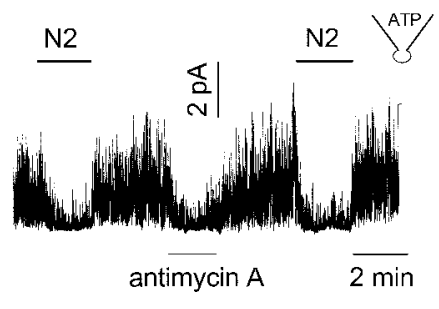

Figure 5. Effects of hypoxia and inhibitors of mitochondrial respiration on granule cell VRAC single channels. $A$, Effects of hypoxia (5 min) performed with pure nitrogen on the $\mathrm{Cl}^{-}$current recorded in the cellattached configuration during a hypotonic stimulation $(220 \mathrm{mOsm}) . I-V$ curves recorded during hypoxia and recovery are illustrated in gray. The holding potential was $-60 \mathrm{mV}$, and the patch was depolarized to $+80 \mathrm{mV}$ with a voltage ramp of $500 \mathrm{msec}$ in duration. $B$, Effects of oligomycin $(2.5$ $\mu \mathrm{g} / \mathrm{ml})$, antimycin A $(10 \mu \mathrm{M})$, and rotenone $(10 \mu \mathrm{M})$ on the VRAC current recorded in an outside-out patch in hypotonic condition $(300$ mOsm). The holding potential was $+50 \mathrm{mV}$. The internal medium contained $6 \mathrm{mM} \mathrm{Cl}^{-}$and $5 \mathrm{~mm}$ ATP. $C$, Reversible effects of oligomycin $(2.5$ $\mu \mathrm{g} / \mathrm{ml}$ ) on the $I-V$ curve of VRAC (illustrated in gray) recorded in an outside-out patch in hypotonic condition. The holding potential was -60 $\mathrm{mV}$, and the patch was depolarized to $+80 \mathrm{mV}$ with a voltage ramp of 500 msec in duration. The internal medium contained $6 \mathrm{mM} \mathrm{Cl}^{-}$and $5 \mathrm{~mm}$ ATP. $D$, Effects of hypoxia, performed with pure nitrogen, and antimycin A on the VRAC current recorded in an outside-out patch in hypotonic conditions $(300 \mathrm{mOsm})$. The holding potential was $+50 \mathrm{mV}$. The internal medium contained $6 \mathrm{mM} \mathrm{Cl}^{-}$and $5 \mathrm{~mm}$ ATP.

(oligomycin, antimycin $\mathrm{A}$, and rotenone) reversibly inhibited $\mathrm{Cl}^{-}$ channel activity in outside-out patches excised in the presence of internal ATP and maintained in hypotonic conditions (300 mOsm). Similar data were obtained with patches excised in the presence of either $5 \mathrm{~mm}$ AMP-PNP or $5 \mathrm{~mm} \mathrm{ATP} / 3 \mathrm{~mm}$ ADP (data not shown). The single-channel conductance of VRAC was not altered by these treatments, and inhibition was observed at all potentials (Fig. $5 C$ ). Finally, Figure $5 D$ shows that hypoxia performed by bubbling nitrogen mimicked the effect of antimycin A in an outside-out patch excised in the presence of internal ATP.

In Figure 6, the effects of hypoxia (nitrogen and oligomycin) were investigated on the native VRAC present in Xenopus oocytes and on the $\mathrm{Cl}^{-}$channel current induced by ICln expression. In these experiments, $\mathrm{K}^{+}$channels were inhibited with $\mathrm{Cs}^{+}$ (substituting $\mathrm{Na}^{+}$) and $\mathrm{Ba}^{2+}$. Hypotonic stimulation of native oocytes $(110 \mathrm{mOsm})$ elicited an inward current measured at a holding potential of $-60 \mathrm{mV}$. The inward current induced by hypotonicity was reversibly inhibited by hypoxia (nitrogen or oligomycin) (Fig. $6 A$ ). The $I-V$ curves of the current induced by hypotonicity in native oocytes is illustrated in Figure $6 B$. As in granule cells, the oocyte volume-activated $\mathrm{Cl}^{-}$current was outwardly rectifying and reversed at $-31 \pm 6 \mathrm{mV}(n=12)$. When $\mathrm{Cl}^{-}$was omitted from the external medium, outward current amplitude was decreased, and the reversal potential was shifted to positive values (not shown). In Figure $6 C$, oocytes were injected 


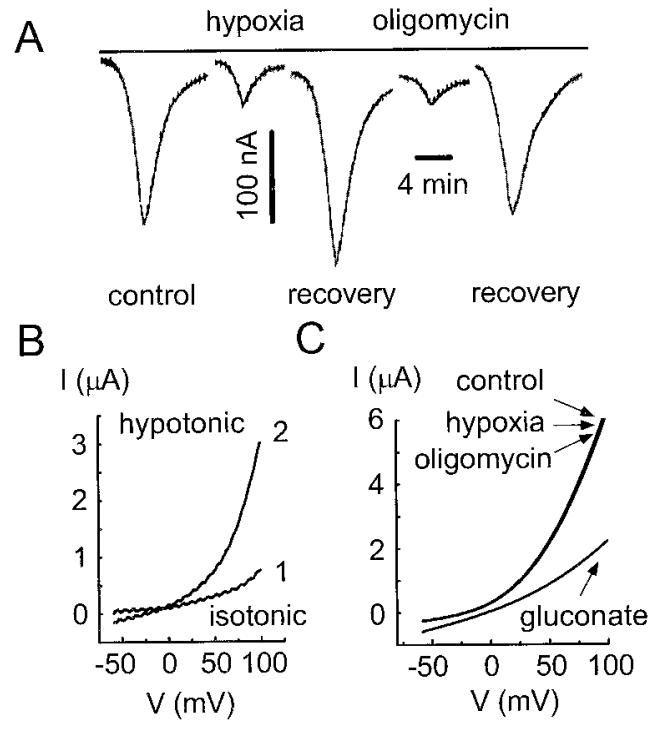

Figure 6. Hypoxic inhibition of VRAC in Xenopus follicular oocyte and lack of effect on ICln-mediated $\mathrm{Cl}^{-}$current. $A$, Reversible inhibition by hypoxia (nitrogen and oligomycin) of the VRAC current in a follicleenclosed oocyte. The holding potential was $-60 \mathrm{mV}$. The oocyte was challenged for $5 \mathrm{~min}$ with a hypotonic solution (110 mOsm) every $20 \mathrm{~min}$. Nitrogen and oligomycin were applied $10 \mathrm{~min}$ before and during the hypotonic stimulation. $B, I-V$ curve of the VRAC current of a follicular oocyte in isotonic $(220 \mathrm{mOsm})$ and hypotonic conditions $(110 \mathrm{mOsm})$. The holding potential was $-60 \mathrm{mV}$, and the oocyte was depolarized to $100 \mathrm{mV}$ with a voltage ramp of $500 \mathrm{msec}$ in duration. $C$, Effects of hypoxia (nitrogen and oligomycin) on the ICln-mediated $\mathrm{Cl}^{-}$current in a defolliculated oocyte. Same parameters as $B$. In this experiment the oocyte was bathed with the standard external solution ( $96 \mathrm{~mm} \mathrm{CsCl} ; 220 \mathrm{mOsm})$. External $\mathrm{Cl}^{-}$concentration was lowered by substituting $96 \mathrm{~mm} \mathrm{Cl}^{-}$with gluconate.

with the mRNA encoding the putative $\mathrm{Cl}^{-}$channel gene ICln. Similar to that of the endogenous volume-activated $\mathrm{Cl}^{-}$current, the $I-V$ curve of ICln was outwardly rectifying, and the reversal potential was $-21 \pm 4 \mathrm{mV}$ in isotonic conditions $(n=7)$. Substitution of external $\mathrm{Cl}^{-}$with gluconate shifted reversal potentials to positive values and decreased the outward current (Fig. $6 C)$. The current was constitutively active in isotonic conditions and did not require cell swelling for activation. Figure $6 C$ shows that neither nitrogen nor oligomycin inhibited the ICln-mediated $\mathrm{Cl}^{-}$current $(n=7)$.

\section{DISCUSSION}

We report the characterization and hypoxic modulation of the volume-regulated anion channels in cerebellar granule cells and demonstrate their contribution to the RVD process. The granule cell VRAC is outwardly rectifying, slowly inactivates during maintained depolarization at positive potentials, and has an anionic permeability of $\mathrm{SCN}^{-}>\mathrm{I}^{-}>\mathrm{Br}^{-}>\mathrm{Cl}^{-}>$taurine $>$ gluconate. The granule cell VRAC is sensitive to the $\mathrm{Cl}^{-}$channel blockers SITS, DIDS, NPPB, and niflumic acid, but is resistant to the calcium-activated $\mathrm{Cl}^{-}$channel blocker 9AC. The single-channel conductance of $36 \mathrm{pS}$ is in the range of the previously reported VRAC in C6 glial and epithelial cells (Solc and Wine, 1991; Okada et al., 1994; Jackson and Strange, 1995).

Activation of granule cell VRAC requires the presence of intracellular nonhydrolytic ATP. Because AMP-PNP, the nonhydrolyzable analog of ATP, can substitute for ATP, it is likely that ATP binding rather than ATP hydrolysis is involved. ATP could possibly bind directly to the channel or bind to an auxiliary regulatory protein. A similar dependence of VRAC activation on internal ATP has been reported previously in other cell types, including hepatocytes, C6 glial cells, T lymphocytes, endothelial cells, and epithelial cells (Jackson et al., 1994; Petersen et al., 1994; Ballatori et al., 1995; Jackson et al., 1996; Manolopoulos et al., 1997).

During hypotonic challenge, we show that granule cells regulate their volume (RVD). RVD was blocked by the $\mathrm{Cl}^{-}$channel inhibitor SITS, suggesting that $\mathrm{Cl}^{-}$channel activation is indeed involved in the process of RVD. Opening of these $\mathrm{Cl}^{-}$channels during cell swelling will allow an efflux of $\mathrm{Cl}^{-}$(and also of organic osmolytes), which is accompanied by cellular water leading to RVD. Because $\mathrm{Cl}^{-}$is predominantly passively distributed across the neuronal membrane, the steady-state equilibrium potential for $\mathrm{Cl}^{-}$ions and thereby the intracellular $\mathrm{Cl}^{-}$concentration is directly proportional to the value of the cell resting membrane potential.

During hypoxia or when normal mitochondrial function was blocked by oligomycin, RVD was impaired and cells remained swollen. In cell-attached, whole-cell, or excised outside-out patches, hypoxia that was performed with either metabolic inhibitors or pure nitrogen reversibly inhibited the opening of VRACs. One possible explanation is that both mitochondrial inhibitors and nitrogen-induced hypoxia may directly affect VRAC channel functions. Another possible explanation is that the effects of hypoxia, antimycin $\mathrm{A}$, rotenone, and oligomycin are mediated by inhibition of mitochondrial respiration. Inhibition of VRAC activation in outside-out patches seems to be in favor of a direct effect on the channels. Indeed, outside-out patches are usually believed to be free of stored energy (i.e., mitochondria). However, differential interference contrast light and high-voltage electron microscopy studies have shown that excised patches are like small pieces of cell rather than pieces of isolated membrane (Sokabe and Sachs, 1991). Indeed, isolated outside-out patches contain cytoskeleton and cellular organelles as well as membrane. The mitochondria present in the patches therefore can provide an energy source. Because VRAC opening requires intracellular ATP, one may suspect that the effects of hypoxia could be mediated by a decrease in intracellular ATP. However, the wholecell and outside-out patches experiments were performed in the presence of $5 \mathrm{~mm}$ internal ATP, suggesting that the effects of hypoxia cannot be explained simply by a drop in intracellular ATP level. Furthermore, granule cell VRAC is insensitive to internal ADP, ruling out its possible involvement during hypoxic inhibition. An alternative mechanism responsible for the hypoxic inhibition of the neuronal cell volume regulation could be related to the involvement of the electron transport chain, which is responsible for the oxidation of NADH and is a site of intense oxygen consumption. A significant portion of consumed oxygen is known to result in the production of radicals and peroxides (Archer et al., 1993). Inhibition of the proximal electron transport chain by rotenone and antimycin A tends to make the cytosol more reduced (increased GSH and NADH levels and decreased activated oxygen species). By contrast, oligomycin, which is a specific blocker of the F1 unit of the mitochondrial ATPase, stimulates mitochondrial respiration and thereby increases the production of activated oxygen species from the electron transport chain. Because the present report shows that rotenone, antimycin A, and oligomycin inhibit VRAC in a similar way, it is unlikely that activated oxygen species and/or the redox status of the cell is involved in this regulation. Further studies will be 
required to gain insights into the exact molecular mechanisms involved in VRAC regulation.

The ubiquitous protein ICln was initially cloned in MDCK cells and induces a constitutively active outwardly rectifying $\mathrm{Cl}^{-}$ channel when expressed in Xenopus oocyte (Paulmichl et al., 1992; Krapivinsky et al., 1994). ICln shares biophysical and pharmacological properties of VRAC (Gschwentner et al., 1996). It has been demonstrated recently that antisense oligonucleotides and a monoclonal anti-ICln antibody inhibit the endogenous VRAC in NIH/3T3 cells and Xenopus oocytes, respectively (Krapivinsky et al., 1994; Gschwentner et al., 1995). These data suggested that ICln encoded VRAC or played a role in the regulation of this type of channel. In the present report, ICln was expressed in Xenopus oocytes, and the effects of hypoxia (nitrogen and oligomycin) were compared on both the native oocyte VRAC (Ackerman et al., 1994; Arellano and Miledi, 1994, 1995; Hand et al., 1997) and ICln-mediated $\mathrm{Cl}^{-}$currents (Paulmichl et al., 1992). Only native oocyte VRAC (similar to granule cell VRAC) is reversibly inhibited by hypoxia and oligomycin. These results suggest that $\mathrm{ICln}$ does not share all the properties of VRAC and that ICln regulation does not depend on cellular energy. Several recent reports (Voets et al., 1996; Buyse et al., 1997) also provide evidence against a direct role of ICln in VRAC.

Chronic hypoxia is associated with cell swelling and subsequent neuronal degeneration (Ames and Nesbett, 1983; Rothman and Olney, 1986; Choi and Rothman, 1990; McManus et al., 1995). Oxygen and glucose deprivation is associated with a large increase in extracellular glutamate concentration, which is believed to mediate most of the toxic effect of neuronal hypoxia (Choi and Rothman, 1990; Choi, 1992, 1994). Both early swelling and later neuronal degeneration are indeed blocked by the addition of NMDA receptor antagonists (Clark and Rothman, 1987; Churchwell et al., 1996). An increase in intracellular $\mathrm{Cl}^{-}$associated with water influx, and subsequent death associated with cell lysis, was shown to be the consequence of chronic hypoxia and NMDA receptor activation (Rothman, 1985). The present work has demonstrated that granule cells VRACs are reversibly inhibited by hypoxia. During anisotonic swelling, hypoxic closing of VRAC channels may represent a short-term physiological adaptive response that limits the leak of essential cellular metabolites (such as amino acids and derivatives, polyols, and methylamines, which are also known to permeate VRAC) and therefore preserves cellular metabolism. Moreover, hypoxic inhibition of VRAC could contribute to limit $\mathrm{Cl}^{-}$influx during NMDA-induced cell depolarization and therefore swelling and cellular injury.

A number of inherited human diseases, including MELAS (mitochondrial myopathy, encephalopathy, lactic acidosis, and stroke-like episodes) and MERRF (myoclonic epilepsy and ragged-red fibers), are associated with a genetic defect of brain mitochondrial functions (Breningstall and Lockman, 1988; Castillo et al., 1995; James et al., 1996; Valanne et al., 1996). These genetic diseases lead to bioenergetically incompetent mitochondria and are associated with significant swelling of brain cells (three- to fourfold). In particular, cortical edema, massive focal brain swelling, and laminar cortical necrosis are the features of the MELAS syndrome. Our finding that VRAC activation is required for proper neuronal volume regulation and is tightly coupled to cellular energy might explain these cytopathic aspects of the MELAS syndrome.

The development of a specific pharmacology for the neuronal VRACs would probably be very useful for the future design of novel therapeutic strategies to limit cellular damage that occurs during brain ischemia and in inherited mitochondrial diseases.

\section{REFERENCES}

Ackerman MJ, Wickman KD, Clapham DE (1994) Hypotonicity activates a native chloride current in Xenopus oocytes. J Gen Physiol 103:153-179.

Ames 3rd A, Nesbett FB (1983) Pathophysiology of ischemic cell death: II. Changes in plasma membrane permeability and cell volume. Stroke $14: 227-233$.

Archer SL, Huang J, Henry T, Peterson D, Weir EK (1993) A redoxbased $\mathrm{O}_{2}$ sensor in rat pulmonary vasculature. Circ Res 73:1100-1112.

Arellano RO, Miledi R (1994) Osmo-dependent $\mathrm{Cl}^{-}$currents activated by cyclic AMP in follicle-enclosed Xenopus oocytes. Proc R Soc Lond B Biol Sci 258:229-235.

Arellano RO, Miledi R (1995) Functional role of follicular cells in the generation of osmolarity-dependent $\mathrm{Cl}^{-}$currents in Xenopus follicles. J Physiol (Lond) 488:351-357.

Ballatori N, Truong AT, Jackson PS, Strange K, Boyer JL (1995) ATP depletion and inactivation of an ATP-sensitive taurine channel by classic ion channel blockers. Mol Pharmacol 48:472-476.

Breningstall GN, Lockman LA (1988) Massive focal brain swelling as a feature of MELAS. Pediatr Neurol 4:366-370.

Buyse G, Voets T, Tytgat J, De Greef C, Droogmans G, Nilius B, Eggermont J (1997) Expression of human pICln and ClC-6 in Xenopus oocytes induces an identical endogenous chloride conductance. J Biol Chem 272:3615-3621.

Castillo M, Kwock L, Green C (1995) MELAS syndrome: imaging and proton MR spectroscopic findings. Am J Neuroradiol 16:233-239.

Choi DW (1992) Excitotoxic cell death. J Neurobiol 23:1261-1276.

Choi DW (1994) Glutamate receptors and the induction of excitotoxic neuronal death. Prog Brain Res 100:47-51.

Choi DW, Rothman SM (1990) The role of glutamate neurotoxicity in hypoxic-ischemic neuronal death. Annu Rev Neurosci 13:171-182.

Churchwell KB, Wright SH, Emma F, Rosenberg PA, Strange K (1996) NMDA receptor activation inhibits neuronal volume regulation after swelling induced by veratridine-stimulated $\mathrm{Na}^{+}$influx in rat cortical cultures. J Neurosci 16:7447-7457.

Clark GD, Rothman SM (1987) Blockade of excitatory amino acid receptors protects anoxic hippocampal slices. Neuroscience 21:665-671.

Gschwentner M, Nagl UO, Woll E, Schmarda A, Ritter M, Paulmichl M (1995) Antisense oligonucleotides suppress cell-volume-induced activation of chloride channels. Pflügers Arch 430:464-470.

Gschwentner M, Susanna A, Schmarda A, Laich A, Nagl UO, Ellemunter H, Deetjen P, Frick J, Paulmichl M (1996) ICln: a chloride channel paramount for cell volume regulation. J Allerg Clin Immunol 98:S98 S101, S105-S106.

Hand M, Morrison R, Strange K (1997) Characterization of volumesensitive organic osmolyte efflux and anion current in Xenopus oocytes. J Membr Biol 157:9-16.

Honoré E, Attali B, Romey G, Lesage F, Barhanin J, Lazdunski M (1992) Different types of $\mathrm{K}^{+}$channel current are generated by different levels of a single mRNA. EMBO J 11:2465-2471.

Jackson PS, Strange K (1995) Single-channel properties of a volumesensitive anion conductance. Current activation occurs by abrupt switching of closed channels to an open state. J Gen Physiol 105:643-660.

Jackson PS, Morrison R, Strange K (1994) The volume-sensitive organic osmolyte-anion channel VSOAC is regulated by nonhydrolytic ATP binding. Am J Physiol 267:C1203-C1209.

Jackson PS, Churchwell K, Ballatori N, Boyer JL, Strange K (1996) Swelling-activated anion conductance in skate hepatocytes: regulation by cell $\mathrm{Cl}^{-}$and ATP. Am J Physiol 270:C57-C66.

James AM, Wei YH, Pang CY, Murphy MP (1996) Altered mitochondrial function in fibroblasts containing MELAS or MERRF mitochondrial DNA mutations. Biochem J 318:401-407.

Krapivinsky GB, Ackerman MJ, Gordon EA, Krapivinsky LD, Clapham DE (1994) Molecular characterization of a swelling-induced chloride conductance regulatory protein, pICln. Cell 76:439-448.

Lipton P (1973) Effects of membrane depolarization on light scattering by cerebral cortical slices. J Physiol (Lond) 231:365-383.

Manolopoulos VG, Voets T, Declercq PE, Droogmans G, Nilius B (1997) Swelling-activated efflux of taurine and other organic osmolytes in endothelial cells. Am J Physiol 273:C214-C222. 
McBain CJ, Traynelis SF, Dingledine R (1990) Regional variation of extracellular space in the hippocampus. Science 249:674-677.

McManus ML, Churchwell KB, Strange K (1995) Regulation of cell volume in health and disease. New Engl J Med 333:1260-1266.

Moran J, Morales-Mulia S, Hernandez-Cruz A, Pasantes-Morales H (1997) Regulatory volume decrease and associated osmolyte fluxes in cerebellar granule neurons are calcium independent. J Neurosci Res 47:144-154.

Okada Y, Petersen CC, Kubo M, Morishima S, Tominaga M (1994) Osmotic swelling activates intermediate-conductance $\mathrm{Cl}^{-}$channels in human intestinal epithelial cells. Jpn J Physiol 44:403-409.

Pasantes-Morales H, Chacon E, Murray RA, Moran J (1994) Properties of osmolyte fluxes activated during regulatory volume decrease in cultured cerebellar granule neurons. J Neurosci Res 37:720-727.

Pasantes-Morales H, Pena Segura C, Garcia O, Morales Mulia MM, Sanchez Olea R, Moran J (1996) Characterization of the volumeactivated taurine pathway in cultured cerebellar granule neurons. Adv Exp Med Biol 403:393-400.

Paulmichl M, Li Y, Wickman K, Ackerman M, Peralta E, Clapham D (1992) New mammalian chloride channel identified by expression cloning. Nature 356:238-241.

Petersen CC, Kubo M, Morishima S, Tominaga M, Okada Y (1994) Single-channel recordings of volume-sensitive $\mathrm{Cl}^{-}$channels in human intestinal epithelial cells. Jpn J Physiol S73-S75.

Rothman SM (1985) The neurotoxicity of excitatory amino acids is produced by passive chloride influx. J Neurosci 5:1483-1489.
Rothman SM, Olney JW (1986) Glutamate and the pathophysiology of hypoxic-ischemic brain damage. Ann Neurol 19:105-111.

Ruknudin A, Song MJ, Sachs F (1991) The ultrastructure of patchclamped membranes: a study using high voltage electron microscopy. J Cell Biol 112:125-134.

Sanchez-Olea R, Morales M, Garcia O, Pasantes-Morales H (1996) Cl channel blockers inhibit the volume-activated efflux of $\mathrm{Cl}$ and taurine in cultured neurons. Am J Physiol 270:C1703-C1708.

Sokabe M, Sachs F (1990) The structure and dynamics of patch-clamped membranes: a study using differential interference contrast light microscopy. J Cell Biol 111:599-606.

Solc CK, Wine JJ (1991) Swelling-induced and depolarization-induced C1-channels in normal and cystic fibrosis epithelial cells. Am J Physiol 261:C658-C674.

Strange K, Emma F, Jackson PS (1996) Cellular and molecular physiology of volume-sensitive anion channels. Am J Physiol 270:C711-C730.

Valanne L, Paetau A, Suomalainen A, Ketonen L, Pihko H (1996) Laminar cortical necrosis in MELAS syndrome: MR and neuropathological observations. Neuropediatrics 27:154-160.

Varming T, Drejer J, Frandsen A, Schousboe A (1996) Characterization of a chemical anoxia model in cerebellar granule neurons using sodium azide: protection by nifedipine and MK-801. J Neurosci Res 44:40-46.

Voets T, Buyse G, Tytgat J, Droogmans G, Eggermont J, Nilius B (1996) The chloride current induced by expression of the protein pICln in Xenopus oocytes differs from the endogenous volume-sensitive chloride current. J Physiol (Lond) 495:441-447. 